\title{
Taste Alteration in Cancer Patients Receiving Chemotherapy: A Cross-Sectional Study
}

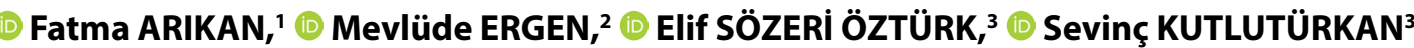

'Department of Internal Medicine Nursing, Akdeniz University, Faculty of Nursing, Antalya-Turkey

${ }^{2}$ Department of Medical Oncology, Memorial Hospital, Oncology Clinic Nurse, Antalya-Turkey

${ }^{3}$ Department of Nursing, Gazi University, Faculty of Health Sciences, Ankara-Turkey

\section{OBJECTIVE}

This study aimed to investigate nutrition in cancer patients, chemotherapy-induced taste alterations and the factors affecting these taste alterations.

\section{METHODS}

This study was planned as a cross-sectional study. Patients who had received chemotherapy at least once and had been on chemotherapy for the last 7-10 days $(n=112)$ were included in this study. The data were collected using the Patient-Generated Subjective Global Assessment, the National Cancer Institute's Common Terminology Criteria for Adverse Events and the Chemotherapy-induced Taste Alteration Scale (CiTAS).

\section{RESULTS}

The CiTAS score was higher in female cancer patients. Patients with nausea $2.19(\mathrm{SD}=1.00)$ and vomiting $3.13(\mathrm{SD}=1.21)$ had higher scores on the taste disorder subscale of the CiTAS, while patients with vomiting $3.00(\mathrm{SD}=1.42)$ had higher scores on the general taste alterations subscale $(\mathrm{p}<0.05)$. Patients with constipation received high scores on the subscales of reduction in intake of the basic tastes, taste disorder, and general taste alterations $2.50(\mathrm{SD}=1.27)(\mathrm{p}<0.05)$. Patients with a lack of appetite obtained high scores on the subscales of reduction in the intake of the basic tastes, taste disorder, phantogeusia, parageusia, and general taste alterations $2.64(\mathrm{SD}=1.29)(\mathrm{p}<0.05)$. Mild malnutrition was observed in $24.6 \%$ of the patients.

\section{CONCLUSION}

This study revealed that taste alteration was higher in female and early-stage patients and more severe in patients with nausea, vomiting, constipation, and mucositis. Taste alteration was found to be greater in patients with poor nutritional status.

Keywords: Chemotherapy; dysgeusia; mucositis; nutrition; symptoms.

Copyright $\odot$ 2019, Turkish Society for Radiation Oncology

\section{Introduction}

Taste alteration is a common side effect in patients receiving systemic chemotherapy.[1] Taste alteration is observed in 55 to $67 \%$ of the patients receiving chemotherapy but is mostly ignored as a symptom. Many chemotherapy drugs commonly used in the treatment of cancer, such as taxane, platinum, adriamycin, and metabolites, cause taste alteration. [2,3]

Chemotherapy-induced taste alterations in cancer patients primarily affect food choice and cause a reduction in food intake. Inadequate food intake regarding 
content and amount causes malnutrition. $[1,4,5] \mathrm{Pa}$ tients with terminal cancer who experienced taste alteration were reported to have lower energy intake and experienced higher weight loss than the patients without taste alteration. Moreover, weight loss, a decrease in muscle mass, and malnutrition intensify chemotherapy-induced symptoms and negatively affect patient outcomes, quality of life, and survival rates.[6,7] In a review of symptoms experienced by cancer patients and their effects on nutrition, chemotherapy-induced taste alterations are reported to reduce caloric intake and cause weight loss leading to protein and vitamin deprivation. [8] Chemotherapy-induced taste alteration results in a decrease in food intake, thus causing weight loss and malnutrition. [9] Two independent studies indicated that chemotherapy-induced taste alteration caused changes in the taste perceptions of sweet, salty, sour and umami tastes, leading to loss of appetite in patients.[10,11]

The unpleasant alteration of taste sensation experienced by patients receiving chemotherapy decreases the quality of their lives.[12] For health care professionals to be able to provide adequate counselling about the taste alteration experienced by their patients, it is necessary to well define the characteristics of this symptom and other related situations. More evidence-based information is required in this regard.[13] The number of studies in Turkey that evaluate chemotherapy-induced taste alteration and nutritional status of cancer patients and related factors is limited. This study was planned to investigate chemotherapy-induced taste alteration in cancer patients and to investigate the factors affecting this side-effect.

\section{Materials and Methods}

\section{Participants and Procedure}

This study was planned as a cross-sectional study. Patients who were over 18 years old, were literate in Turkish, had received chemotherapy at least once, had been on chemotherapy for the last 7-10 days, and reported taste alteration after receiving chemotherapy was enrolled in this study. However, patients receiving head and neck radiotherapy were not included in this study. The research data were collected from 122 patients who met the research inclusion criteria. After receiving information on the patients who agreed to participate in this study, the data were collected in one session using the face-to-face interview method, between January and June 2016.

\section{Data Collection and Measurements}

The research data were collected using the Patient Characteristics Identification Form and the PatientGenerated Subjective Global Assessment (PG-SGA). Oral mucositis was evaluated using the National Cancer Institute's Common Terminology Criteria for Adverse Events version 4.03 (NCI-CTCAE v4.03) and the Chemotherapy-induced Taste Alteration Scale (CiTAS). The form describing patient characteristics consisted of two parts. The first part included patients' sociodemographic characteristics, such as age, gender, marital status, educational status, and income status. The second part consisted of questions regarding cancer patient characteristics, such as the type of cancer, duration of diagnosis, presence or absence of metastasis, chemotherapy regimen, and the number of cures.

The Patient-Generated Subjective Global Assessment (PG-SGA) was used to assess the nutritional status and symptoms of patients. The SGA was completed as described by Detsky et al. (1987), and the scored PGSGA was completed as described by Ottery (1996). Each patient was classified as well-nourished (SGA A), moderately nourished, or suspected of being malnourished (SGA B) or severely malnourished (SGA C).[14,15] Questions about the symptoms of nausea, vomiting, diarrhea, constipation, lack of appetite, and fatigue that affect patient nutrition were included in the scale.

The National Cancer Institute's Common Terminology Criteria for Adverse Events version 4.03 (NCICTCAE v4.03) was used in evaluating oral mucositis. According to this, oral mucositis was scored between grade 0 (none) - grade 5 (death).[16]

The Chemotherapy-induced Taste Alteration Scale (CiTAS) with 18 items and four sub-dimensions was developed by Kano and Kanda.[17] Sözeri and Kutlutürkan (2014) conducted Turkish validity and reliability studies for the scale.[18] The CiTAS is a 5-point Likert type scale. The scale consists of four subscales. The subscale of reduction in intake of basic tastes (2-6 items) is used to assess individuals' perceptions for bitter, sweet, salty, sour, and umami tastes. The taste disorder subscale (13-18 items) evaluates the relationship between changes in taste sensation and nausea/vomiting, change in the sense of smell, difficulty in eating hot food/fatty food/meat, and loss of appetite. The phantogeusia and parageusia subscales (10-12 items) are used to evaluate individuals' phantogeusia and parageusia experiences. The general taste alteration subscale (1, 7-9 items) assesses ageusia, cacogeusia and hypogeusia in patients. The scores obtained from the subscales instead of the total scale score are used in evaluating 
the scores received from the scale. The scores obtained from the subscales are calculated by adding the scores received from the subscale items in question and then dividing the obtained total score with the total number of items. The maximum and minimum scores for the subscales are 5 and 1, respectively. An increase in scores on the scale indicates an increase in the severity of the individual's taste alteration and disorder.[17,18] In this study, Cronbach's alpha values for the subscales were found to be $0.86,0.82,0.94$, and 0.88 , respectively.

\section{Data Analysis}

Data analysis was performed using SPSS Version 22.0 (IBM Corporation, New York, USA). The KolmogorovSmirnov test was used to evaluate the normal distribution of data. Number, percentage, mean, and standard deviation were used for descriptive statistics. Independent samples t-test and one-way ANOVA were used to find out the differences between scale mean scores of independent variables and a $p$-value $<0.05$ was considered statistically significant.

\section{Results}

\section{Patient Characteristics and Clinical Features}

The mean age of the participants in this study was $53.51(\mathrm{SD}=14.15)$ and $50.8 \%$ of them were male, $82.8 \%$ were married, $43.4 \%$ were primary school graduates, $75.4 \%$ were unemployed, and $51.6 \%$ had a steady income. In addition, the cancer diagnoses of the patients were breast cancer (24.6\%), lung cancer (19.7\%) and head and neck cancer (19.7\%). The mean duration of the diagnosis was $19.05 \pm 26.30$ months; $68 \%$ of the diagnosis time was one year or less, $77 \%$ of the patients had no metastasis, and $41 \%$ and $34.4 \%$ of the patients were receiving platinum and taxane chemotherapy drugs, respectively. The mean number of chemotherapy cures received by the patients was $3.83(\mathrm{SD}=2.93)$ and $45.9 \%$ of the patients received two chemotherapy cures (Table 1).

The mean body mass index of the patients was 25.97 $(\mathrm{SD}=4.68)$, and $43.4 \%$ of them were in the range of 18.5 $\mathrm{kg} / \mathrm{m}^{2}-24.95 \mathrm{~kg} / \mathrm{m}^{2}$. Evaluation of the deterioration of oral mucosa of the patients showed that only $7.4 \%$ had grade 1 mucositis, 93.4\% did not smoke cigarettes, and $86.1 \%$ performed oral care. The nutritional status of patients was assessed according to the SGA evaluation; $75.4 \%$ of the patients were well-nourished, while $24.6 \%$ were moderately nourished or suspected of being malnourished (Table 1). Chemotherapy-induced symptoms were recorded in $55.7 \%$ of the patients, and their
Table 1 Sociodemographic and disease characteristics
of cancer patients

\begin{tabular}{|c|c|c|}
\hline Characteristics $(n=122)$ & n (\%) & Mean \pm SD \\
\hline Age & & $53.51(14.15)$ \\
\hline Under 40 & $19(15.6)$ & \\
\hline 40-59 & $57(46.7)$ & \\
\hline 60 and over & $46(37.7)$ & \\
\hline \multicolumn{3}{|l|}{ Gender } \\
\hline Female & $60(49.2)$ & \\
\hline Male & $62(50.8)$ & \\
\hline \multicolumn{3}{|l|}{ Marital status } \\
\hline Married & $101(82.8)$ & \\
\hline Single & $21(17.2)$ & \\
\hline \multicolumn{3}{|l|}{ Education } \\
\hline Primary school & $53(43.4)$ & \\
\hline Secondary school & $32(26.2)$ & \\
\hline University & $37(30.4)$ & \\
\hline \multicolumn{3}{|l|}{ Working status } \\
\hline Employed & $30(24.6)$ & \\
\hline Unemployed & $92(75.4)$ & \\
\hline \multicolumn{3}{|l|}{ Monthly income-expense } \\
\hline Balanced & $63(51.6)$ & \\
\hline Partially balanced & $35(28.7)$ & \\
\hline Unbalanced & $24(19.7)$ & \\
\hline Disease characteristics & n (\%) & Mean (SD) \\
\hline \multicolumn{3}{|l|}{ Cancer diagnosis } \\
\hline Breast & $30(24.6)$ & \\
\hline Lung & $24(19.7)$ & \\
\hline GIS & $16(13.1)$ & \\
\hline Head and neck & $24(19.7)$ & \\
\hline Gynecological & $7(5.7)$ & \\
\hline Testicular-prostate & $8(6.5)$ & \\
\hline Other* & $7(5.7)$ & \\
\hline Diagnosis time (years) & & $19.05(26.30)$ \\
\hline$\leq 1$ & $83(68.0)$ & \\
\hline $1-5$ & $29(23.8)$ & \\
\hline 6 years and over & $10(8.2)$ & \\
\hline \multicolumn{3}{|l|}{ Metastasis } \\
\hline Yes & $94(77.0)$ & \\
\hline No & $28(23.0)$ & \\
\hline \multicolumn{3}{|l|}{ Chemotherapy drugs } \\
\hline Taxane & $42(34.4)$ & \\
\hline Adriamycin & $16(13.1)$ & \\
\hline Platinum & $50(41.0)$ & \\
\hline Metabolites & $11(9.0)$ & \\
\hline Other & $3(2.5)$ & \\
\hline Number of chemotherapy cycles & & $3.83(2.93)$ \\
\hline 2 & $56(45.9)$ & \\
\hline 3 & $19(15.6)$ & \\
\hline 4 & $20(16.4)$ & \\
\hline 5 and over & $27(22.1)$ & \\
\hline
\end{tabular}

nutritional status was affected by nausea (23\%), vomiting (4.9\%), diarrhea (12.3\%), constipation (22.1\%), and inappetence (20.5\%) (Table 2). 


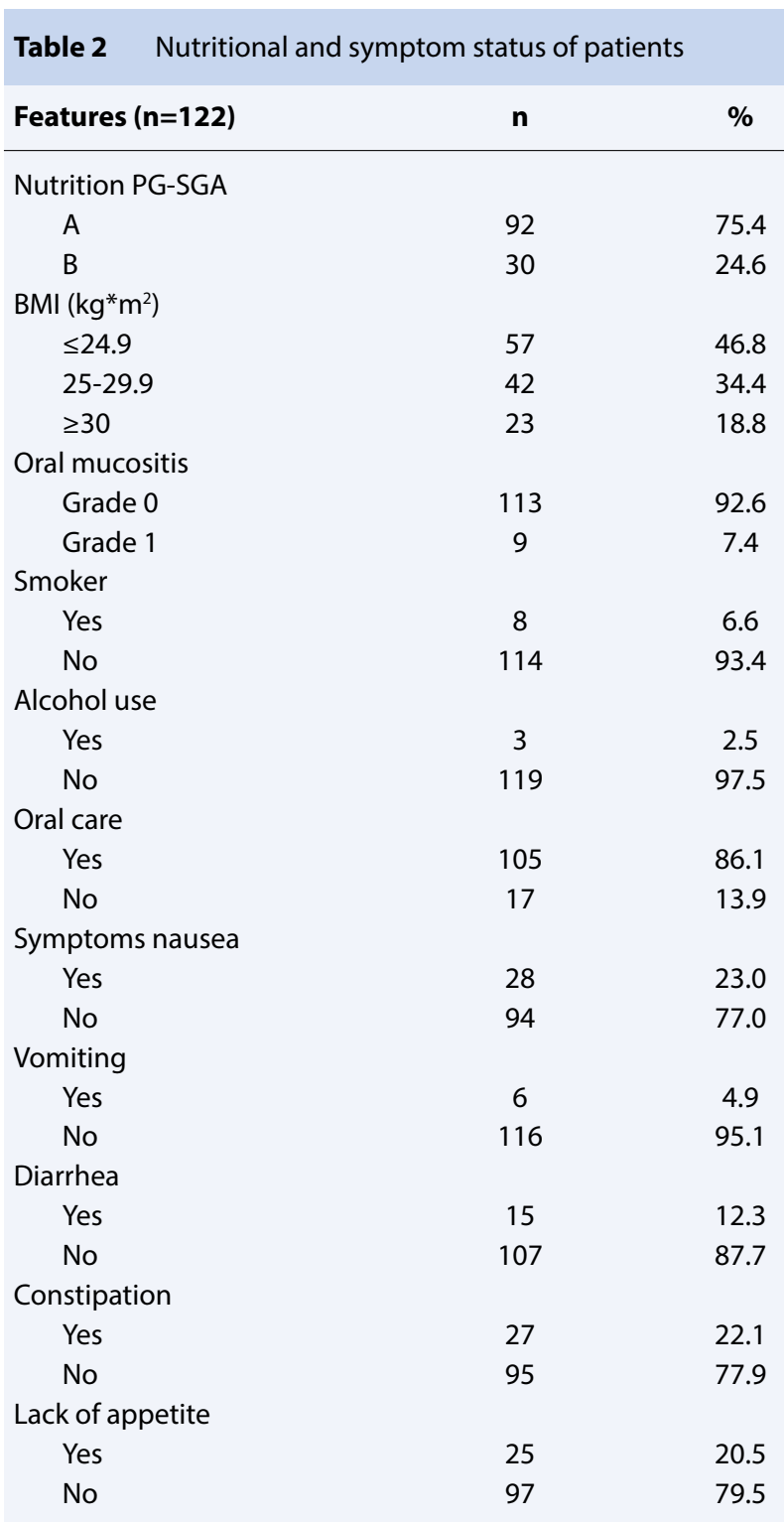

A: Well-nourished; B: Moderately or suspected of being malnourished; *Unknown Primer (5), Sarkom (2).

\section{Characteristics of Taste Alteration}

The CiTAS mean scores of the participant cancer patients did not vary based on gender and age $(p>0.05)$, but the CiTAS mean scores of female patients were higher than those of male patients. The CiTAS mean score on the taste alteration-induced discomfort subscale received by patients without metastatic cancer $(2.19 \pm 0.99)$ was found to be higher compared to the score of the patients with metastasis $(1.81 \pm 0.82)$. The CiTAS mean scores on the taste disorder subscale (assessing the relationship between changes in taste sensation and nausea-vomiting, change in smell sensation, difficulty in hot food/fatty food/meat consump- tion, and loss of appetite) were significantly different between patients with and without metastatic cancer $(\mathrm{p}<0.05)$. However, the CiTAS mean scores did not vary significantly concerning the type of their chemotherapy regimen $(\mathrm{p}>0.05)$ (Table 3$)$.

\section{Taste Alteration and Symptoms}

No statistically significant differences were found between the CiTAS mean scores of the patients with and without diarrhea and fatigue symptoms $(p>0.05)$. The mean score of patients with nausea on the second subscale (taste disorder) of the CiTAS was found to be significantly higher than the score of the patients without nausea. The mean scores of patients with vomiting on the second (taste disorder) and fourth (general taste alterations) subscales of the CiTAS were found to be higher than of those without vomiting $(\mathrm{p}<0.05)$. The mean scores of patients with constipation on the first (reduction in intake of basic tastes), second (taste disorder) and fourth (general taste alterations) subscales of the CiTAS were found to be higher than of the patients without constipation $(\mathrm{p}<0.05)$. The mean scores of the patients with lack of appetite on the first (reduction in intake of basic tastes) $(\mathrm{p}=0.015)$, second (taste disorder) $(\mathrm{p}<0.001)$, third (phantogeusia and parageusia) $(\mathrm{p}<0.001)$, and fourth (general taste alterations) $(\mathrm{p}<0.001)$ subscales of the CiTAS were found to be higher than of those without lack of appetite (Table 4).

\section{Taste Alteration and Mucositis}

The mean scores of the patients with oral mucositis on the first (reduction in intake of basic tastes), second (taste disorder), third (phantogeusia and parageusia), and fourth (general taste alterations) subscales of the CiTAS were found to be higher than the patients without oral mucositis; however, only the difference in the second subscale was statistically significant $(\mathrm{p}=0.028)$ (Table 4).

\section{Taste Alteration and Nutrition}

The mean scores of the patients with mild malnutrition on the first (reduction in intake of basic tastes), second (taste disorder), third (phantogeusia and parageusia), and fourth (general taste alterations) subscales of the CiTAS were found to be higher than those of wellnourished patients $(\mathrm{p}<0.001)$ (Table 4$)$.

\section{Discussion}

Treatment-induced taste alteration in cancer patients is also affected by individual and clinical characteristics of the individuals. In the present study, female pa- 
Table 3 Differences in the taste scale mean scores by sociodemographic and disease characteristics of cancer patients receiving chemotherapy

\begin{tabular}{|c|c|c|c|c|}
\hline & $\begin{array}{c}\text { Decline in Basic } \\
\text { Taste } \\
\text { Mean (SD) }\end{array}$ & $\begin{array}{l}\text { Discomfort } \\
\text { Mean (SD) }\end{array}$ & $\begin{array}{c}\text { Phantogeusia } \\
\text { and Parageusia } \\
\text { Mean (SD) }\end{array}$ & $\begin{array}{l}\text { General Taste } \\
\text { Alterations } \\
\text { Mean (SD) }\end{array}$ \\
\hline \multicolumn{5}{|l|}{ Gender } \\
\hline Female & $1.58(0.82)$ & $1.95(0.92)$ & $1.93(1.18)$ & $2.07(1.19)$ \\
\hline Male & $1.54(0.91)$ & $1.84(0.83)$ & $1.63(1.05)$ & $1.86(1.07)$ \\
\hline t/P-Value & $0.220 / 0.826$ & $0.717 / 0.475$ & $1.474 / 0.143$ & $1.067 / 0.288$ \\
\hline \multicolumn{5}{|l|}{ Age } \\
\hline 40 and under & $1.48(0.58)$ & $1.48(0.78)$ & $1.91(1.05)$ & $1.86(0.83)$ \\
\hline $41-59$ & $1.50(0.80)$ & $1.50(0.92)$ & $1.76(1.15)$ & $1.96(1.05)$ \\
\hline 60 and over & $1.66(1.03)$ & $1.66(0.85)$ & $1.76(1.14)$ & $2.01(1.25)$ \\
\hline F/P-Value & $0.560 / 0.573$ & $0.787 / 0.458$ & $0.138 / 0.871$ & $0.122 / 0.885$ \\
\hline \multicolumn{5}{|l|}{ BMI( ( kg* $\left.\left.{ }^{*}\right)^{2}\right)$} \\
\hline$\leq 24.9$ & $1.42(0.73)$ & $1.86(0.86)$ & $1.68(1.03)$ & $1.78(0.96)$ \\
\hline $25-29.9$ & $1.59(0.92)$ & $1.83(0.80)$ & $1.82(1.24)$ & $2.07(1.25)$ \\
\hline$\geq 30$ & $1.84(1.02)$ & $2.11(1.03)$ & $1.97(1.13)$ & $2.20(1.06)$ \\
\hline F/P-Value & $1.976 / 0.143$ & $0.866 / 0.423$ & $0.565 / 0.570$ & $1.517 / 0.223$ \\
\hline \multicolumn{5}{|l|}{ Cancer diagnosis } \\
\hline Breast & $1.54(0.85)$ & $2.10(1.01)$ & $1.98(1.23)$ & $2.10(1.17)$ \\
\hline Lung & $1.52(0.94)$ & $1.76(0.76)$ & $1.97(1.21)$ & $2.12(1.13)$ \\
\hline GIS & $1.42(0.71)$ & $1.83(0.67)$ & $1.61(1.11)$ & $1.71(0.82)$ \\
\hline Head and neck & $1.80(0.72)$ & $2.00(0.56)$ & $1.90(0.87)$ & $2.67(0.89)$ \\
\hline Gynecological & $1.47(0.67)$ & $1.47(0.81)$ & $1.29(0.45)$ & $1.65(1.14)$ \\
\hline Testicular-prostate & $1.54(0.78)$ & $1.85(1.01)$ & $1.33(0.57)$ & $1.32(0.37)$ \\
\hline Other & $1.66(1.03)$ & $2.25(1.31)$ & $1.33(081)$ & $1.62(0.97)$ \\
\hline F/P-Value & $0.300 / 0.952$ & $0.727 / 0.649$ & $0.896 / 0.513$ & $1.311 / 0.251$ \\
\hline \multicolumn{5}{|l|}{ Diagnosis time } \\
\hline$\leq 1$ year & $1.56(0.92)$ & $1.99(0.94)$ & $1.85(1.18)$ & $1.98(1.11)$ \\
\hline $1-5$ years & $1.62(0.76)$ & $1.65(0.54)$ & $1.52(0.88)$ & $1.96(1.10)$ \\
\hline 6 years and over & $1.40(0.69)$ & $1.80(0.98)$ & $1.96(1.25)$ & $1.80(1.03)$ \\
\hline F/P-Value & $0.236 / 0.790$ & $1.729 / 0.182$ & $1.045 / 0.355$ & $0.129 / 0.879$ \\
\hline \multicolumn{5}{|l|}{ Chemotherapy } \\
\hline Taxane & $1.50(0.77)$ & $1.84(0.81)$ & $1.57(0.98)$ & $1.92(1.12)$ \\
\hline Adriamycin & $1.68(0.85)$ & $2.33(1.16)$ & $2.39(1.34)$ & $2.25(1.02)$ \\
\hline Platinum & $1.58(1.00)$ & $1.89(0.85)$ & $1.81(1.20)$ & $1.97(1.16)$ \\
\hline Metabolites & $1.56(0.71)$ & $1.53(0.63)$ & $1.63(0.80)$ & $1.65(0.67)$ \\
\hline F/P Value & $0.156 / 0.960$ & $F=1.536 / 0.196$ & $1.650 / 0.166$ & $0.500 / 0.736$ \\
\hline \multicolumn{5}{|l|}{ Metastasis } \\
\hline Yes & $1.58(0.91)$ & $1.81(0.82)$ & $1.75(1.10)$ & $1.95(1.13)$ \\
\hline No & $14.9(0.72)$ & $2.19(0.99)$ & 1.90 (1.19) & $2(0.97)$ \\
\hline t/P-Value & $0.479 / 0.632$ & $-2.017 / 0.043$ & $-0.630 / 0.530$ & $-0.179 / 0.858$ \\
\hline
\end{tabular}

$\mathrm{t}=$ student $\mathrm{t}$-test $; \mathrm{F}=\mathrm{ANOVA} ; \mathrm{SD}=$ Standard Deviation.

tients were found to have higher mean scores for taste alterations, such as phantogeusia, parageusia, ageusia, cacogeusia, and hypogeusia. In a study involving patients with solid tumors, no statistically significant difference was found between taste alterations of male and female patients, but female experienced taste alteration twice as much as male patients.[5] Many studies showed that female cancer patients experienced more taste alteration. $[13,19]$ The taxane chemotherapy regimen was reported to cause taste deterioration in female breast cancer patients.[3] Other previous studies with patients receiving chemotherapy found that female patients experienced more taste deterioration.[2,20,21] However, some studies reported no difference in taste 
Table 4 Differences in the taste scale mean scores by symptom status of cancer patients receiving chemotherapy

\begin{tabular}{|c|c|c|c|c|}
\hline Symptom & $\begin{array}{c}\text { Decline in Basic } \\
\text { Taste } \\
\text { Mean (SD) }\end{array}$ & $\begin{array}{l}\text { Discomfort } \\
\text { Mean (SD) }\end{array}$ & $\begin{array}{c}\text { Phantogeusia } \\
\text { and Parageusia } \\
\text { Mean (SD) }\end{array}$ & $\begin{array}{c}\text { General Taste } \\
\text { Alterations } \\
\text { Mean (SD) }\end{array}$ \\
\hline \multicolumn{5}{|l|}{ Nausea } \\
\hline Yes & $1.59(1.03)$ & $2.19(1.00)$ & $2.08(1.27)$ & $2.08(1.18)$ \\
\hline No & $1.55(0.81)$ & $1.81(0.82)$ & $1.69(1.06)$ & $1.93(1.07)$ \\
\hline t/P-Value & $0.211 / 0.833$ & $2.017 / 0.044$ & $-1.598 / 0.113$ & $-0.669 / 0.505$ \\
\hline \multicolumn{5}{|l|}{ Vomiting } \\
\hline Yes & $1.80(1.23)$ & $3.13(1.21)$ & $2.61(1.42)$ & $3.00(1.42)$ \\
\hline No & $1.55(0.85)$ & $1.83(0.81)$ & 1.74 (1.09) & $1.91(1.05)$ \\
\hline t/P Value & $0.685 / 0.495$ & $3.727 /<0.001$ & $-1.858 / 0.066$ & $2.409 / 0.017$ \\
\hline \multicolumn{5}{|l|}{ Diarrhea } \\
\hline Yes & $1.34(0.63)$ & $1.97(0.78)$ & $1.48(0.60)$ & $2.08(1.01)$ \\
\hline No & 1.59 (0.89) & $1.88(0.89)$ & $1.82(1.17)$ & $1.95(1.1)$ \\
\hline t/P-Value & - 1.025/0.307 & $-0.364 / 0.200$ & $1.096 / 0.717$ & $-0.436 / 0.694$ \\
\hline \multicolumn{5}{|l|}{ Constipation } \\
\hline Yes & $2.00(1.10)$ & $2.22(1.90)$ & $2.22(1.35)$ & $2.50(1.27)$ \\
\hline No & $1.43(1.43)$ & $1.80(0.85)$ & $1.66(1.02)$ & $1.81(0.99)$ \\
\hline t/P-Value & $-3.119 / 0.002$ & $2.236 / 0.027$ & $-2.318 / 0.022$ & $2.624 / 0.003$ \\
\hline \multicolumn{5}{|c|}{ Lack of appetite } \\
\hline Yes & $1.93(1.11)$ & $2.58(0.98)$ & $2.48(1.52)$ & $2.64(1.29)$ \\
\hline No & $1.46(0.77)$ & $1.72(0.76)$ & $1.60(0.92)$ & 1.79 (0.97) \\
\hline t/P-Value & $-2.458 / 0.015$ & $-4.704 / 0.001$ & $-3.621 / 0.001$ & $-3.602 / 0.001$ \\
\hline \multicolumn{5}{|c|}{ Nutritional status (PG-SGA) } \\
\hline A & $1.38(0.68)$ & $1.64(0.68)$ & $1.57(0.96)$ & $1.70(0.91)$ \\
\hline B & $2.10(1.13)$ & $2.67(0.97)$ & $2.44(1.33)$ & $2.78(1.22)$ \\
\hline t/P-Value & $-4.209 / 0.001$ & $-6.393 / 0.001$ & $-3.810 / 0.001$ & $-5.161 / 0.001$ \\
\hline \multicolumn{5}{|c|}{ Oral mucositis } \\
\hline Grade 0 & $1.54(0.87)$ & $1.85(0.84)$ & $1.74(1.07)$ & $1.92(1.08)$ \\
\hline Grade 1 & $1.75(0.87)$ & $2.51(0.87)$ & $2.25(1.12)$ & $2.52(1.96$ \\
\hline t/P-Value & $-0.691 / 0.0491$ & $-2.230 / 0.028$ & $-1.312 / 0.192$ & $-1.602 / 0.112$ \\
\hline
\end{tabular}

$\mathrm{t}=$ student $\mathrm{t}$-test; $\mathrm{SD}=$ Standard Deviation.

sensation between genders.[5,7] Although the reason for the difference in taste alterations by gender is not clearly known, female patients are more sensitive to taste alterations than men.[21,22]

In this study, taste alteration did not vary by age. In a study examining taste alteration in cancer patients after receiving six cures of chemotherapy application, taste alteration was found to be more frequent in young patients. Another study reported that female and young patients experienced more frequent taste alterations.[13]

\section{Taste Alteration and Clinical Features}

The present study showed that diagnosis and chemotherapy regimen did not cause significant variations in patient taste alteration. The mean scores of the patients without metastatic cancer (patients who were in the early stage) on the taste disorder subscale of the CiTAS (which assesses the relationship between changes in taste sensation and nausea-vomiting, change in smell sensation, difficulty in hot food/fatty food/meat consumption, and loss of appetite) were higher than the patients with metastatic cancer. This result suggests that early-stage patients were more susceptible to taste alteration. Previous studies showed variable results compared with the present study. A study on lung cancer patients reported no relationship between taste alteration and cancer type, stage, treatment type and duration.[13] A survey of the patients with different cancer diagnoses showed that most patients experienced taste alteration at the beginning of chemotherapy, and that breast cancer patients experienced more frequent 
taste alteration.[2] A study with 184 patients receiving chemotherapy reported that taste alteration was independent of diagnosis and disease history.[23] Moreover, breast and colorectal cancer patients experienced taste alteration; there was no difference between diagnoses regarding symptoms.[14] Patients with breast and gynecological cancer did not show significant differences in taste alteration based on the diagnosis.[4]

\section{Taste Alteration and Symptoms}

Chemotherapy-induced nausea is a significant problem in clinical settings, and approximately $50 \%$ of the patients experience this disturbing symptom.[24] In the present study, patients with nausea showed a higher taste disorder level than patients without nausea. The mean scores of the patients with vomiting on the general taste alteration and taste disorder subscales were higher than the patients without vomiting. The mean scores of the patients with inappetence on the subscales of taste disorder, phantogeusia and parageusia, and general taste alterations were higher compared with the patients without lack of appetite. Taste alteration may cause loss of appetite, food aversion and intake reduction, and increase the risk of malnutrition.[3] Patients with dysgeusia were reported to have higher nausea and vomiting scores and lower quality of life. [12] Another study reported that taste alteration and vomiting/nausea were related.[2]

In the present study, patients with constipation received higher mean scores on the subscales of reduction in the intake of basic tastes, taste disorder, and general taste alterations than the patients without constipation. The basic tastes subscale and taste disorder subscale evaluate the relationship between changes in taste sensation and nausea-vomiting, change in the sense of smell, difficulty in eating hot food/fatty food/ meat, and loss of appetite. High mean scores based on these scales are anticipated in cancer patients, in addition to the accompanying constipation symptoms. Taste alteration was reported to cause loss of appetite. Constipation was reported to be the most common gastrointestinal symptom in terminal stage cancer patients with poor appetite.[25,26]

In the present study, patients had oral mucositis at grade 0 and 1 , and patients with oral mucositis of grade 1 had a higher taste disorder level and experienced general taste alterations. Chemotherapy-induced oral mucositis causes deterioration of taste receptors. [1] $\mathrm{Pa}$ tients with oral mucositis are more likely to experience overall taste alterations, and to encounter problems, such as nausea and vomiting, changes in the sense of smell, difficulty in eating hot food/fatty food/meat, and loss of appetite, due to these alterations. Taste alterations, such as chemotherapy-induced oral mucositis, were found to be related to dysgeusia.[1,27] The present study showed higher taste alterations in patients with nausea, vomiting, loss of appetite and mucositis, corroborating previous studies.

\section{Taste Alteration and Nutrition}

In the present study, the mean scores of the patients with mild malnutrition in all subscales of the CiTAS were found to be higher than the patients with good nutritional status. Patients experiencing the taste and smell alterations have been found to have a higher risk of malnutrition, and the taste and smell alterations have also been associated with oral dryness, feeling full quickly, and fatigue.[5] Patients with small extracellular lung cancer, and receiving cisplatin and paclitaxel chemotherapy, reported a loss of appetite with bitterness and unpleasant taste in the mouth[28] The present study corroborates previous studies that indicate a loss of appetite and reduction in food intake in cancer patients who experienced taste alteration.[1,29]

\section{Limitations}

The most significant limitation of this study is that the research data have been collected and evaluated using patients' own statements. The empowerment of this evaluation requires experimental measures of taste perception and identification. Another limitation of this study is that this study has been conducted with patients with different diagnoses and different chemotherapy regimens. Due to the various side effects of chemotherapy drugs, studies should be conducted on patients undergoing the same type of chemotherapy and over longer time intervals to strengthen clinical outcomes associated with taste alteration.

\section{Conclusion}

This study revealed that taste alteration was higher in female and early-stage patients and more severe in patients with nausea, vomiting, constipation and mucositis. Taste alteration was greater in patients with poor nutritional status. Therefore, continuous evaluation of the chemotherapy-induced taste alterations in cancer patients in oncology clinics, and preventive interventions for symptoms, such as nausea, vomiting, constipation and mucositis, affecting taste alteration might reduce taste alteration in patients and increase the quality of their lives. In consultations with patients 
and their relatives in oncology clinics, taste alterations should be considered in the formulation of nutrition programs and preparation of foods for patients.

Peer-review: Externally peer-reviewed.

Conflict of Interest: The authors declare no conflict of interest.

Ethics Committee Approval: Ethical approval was obtained from the ethics committee before conducting this study (Date: 08.01.2016. No: 18/2016), which was in accordance with the Helsinki Declaration, and by voluntary action. Written and oral consents were obtained from the participants in this study.

Financial Support: This research did not receive any specific grant from funding agencies in the public, commercial, or not-for-profit sectors.

Authorship contributions: Concept - F.A., M.E.; Design F.A., M.E, E.S.Ö., S.K.; Supervision - F.A.; Materials - F.A., E.S.Ö., S.K.; Data collection and/or processing - F.A., M.E.; Data analysis and/or interpretation - F.A., M.E., E.S.Ö.; Literature search - F.A., M.E, E.S.Ö., S.K.; Writing - F.A., M.E., S.K.; Critical review - F.A., M.E, E.S.Ö., S.K.

\section{References}

1. Okada N, Hanafusa T, Abe S, Sato C, Nakamura T, Teraoka K, et al. Evaluation of the risk factors associated with high-dose chemotherapy-induced dysgeusia in patients undergoing autologous hematopoietic stem cell transplantation: possible usefulness of cryotherapy in dysgeusia prevention. Support Care Cancer 2016;24(9):3979-85.

2. Bernhardson BM, Tishelman C, Rutqvist LE. Self-reported taste and smell changes during cancer chemotherapy. Support Care Cancer 2008;16,275-83.

3. Speck RM, DeMichele A, Farrar JT, Hennessy S, Mao JJ, Stineman MG, et al. Taste alteration in breast cancer patients treated with taxane chemotherapy: experience, effect, and coping strategies. Support Care Cancer 2013;21:549-55.

4. Gamper EM, Zabernigg A, Wintner, LM, Giesinger J M., Oberguggenberger A, Kemmler G, et al. Coming to your senses: detecting taste and smell alterations in chemotherapy patients. A systematic review. J Pain Symptom Manage 2012;44(6):880-95.

5. Spotten L, Corish C, Lorton C, Dhuibhir PU, O'Donoghue N, O'Connor B, et al. Subjective taste and smell changes in treatment-naive people with solid tumours. Support Care Cancer 2016; 24:3201-08.

6. Hutton JL, Baracos VE, Wismer WV. Chemosensory dysfunction is a primary factor in the evolution of declining nutritional status and quality of life in patients with advanced cancer. J Pain Symptom Manage 2007;33:156-65.

7. Brisbois TD, de Kock IH, Watanabe SM., Baracos VE, Wismer WV. Characterization of chemosensory alterations in advanced cancer reveals specific chemosensory phenotypes impacting dietary intake and quality of life. J Pain Symptom Manage. 2011;41:673-83.

8. Grant M, Kravits K. Symptoms and their impact on nutrition. In Semin Oncol Nurs 2000;16:113-21.

9. Ravasco P. Aspects of taste and compliance in patients with cancer. Eur J Oncol Nur 2005;9:84-91.

10. Sánchez-Lara K, Sosa-Sánchez R, Green-Renner D, Rodríguez C, Laviano A, Motola-Kuba D, et al. Influence of taste disorders on dietary behaviors in cancer patients under chemotherapy. Nutr J 2010;24:9-15.

11. Coa KI, Epstein JB, Ettinger D, Jatoi A, McManus K, Platek ME, et al. The impact of cancer treatment on the diets and food preferences of patients receiving outpatient treatment. Nutr Cancer 2015;67:339-53.

12. Ponticelli E, Clari M, Frigerio S, De Clemente A, Bergese I, Scavino E, et al. Dysgeusia and health-related quality of life of cancer patients receiving chemotherapy: A cross-sectional study. Eur J Cancer Care 2017;26(2)1-7.

12. McGreevy J, Orrevall Y, Belqaid K, Wismer W, Tishelman C, Bernhardson. Characteristics of taste and smell alterations reported by patients after starting treatment for lung cancer. Support Care Cancer 2014;22:2635-44.

13. Ottery FD. Definition of standardized nutritional assessment and interventional pathways in oncology. Nutrition 1996;12:15-9.

14. Bauer J, Capra S, Ferguson M. Use of the scored Patient-Generated Subjective Global Assessment (PGSGA) as a nutrition assessment tool in patients with cancer. Eur J Clin Nutr 2002;56:779-85.

15.https://evs.nci.nih.gov/ftp1/CTCAE/CTCAE_4.03/ CTCAE_4.03_2010-06-14_QuickReference_5x7.pdf

16. Kano T, Kanda K. Development and validation of a chemotherapy-induced taste alteration scale. Oncol Nurs Forum 2013;40,79-85.

17. Sozeri E, Kutlutürkan S. The validity and reliability of Turkish version of the chemotherapy-induced taste alteration scale (CiTAS). Clin Nurs Res 2018;27(2):235-49.

18. Epstein JB, Phillips N, Parry J, Epstein MS, Nevill T, Stevenson-Moore P. Quality of life, taste, olfactory and oral function following high-dose chemotherapy and allogeneic hematopoietic cell transplantation. Bone Marrow Transplant 2002;30:785-92.

19.Zabernigg A, Gamper EM, Giesinger J M, Rumpold $\mathrm{G}$, Kemmler G, Gattringer K, et al. Taste alterations in 
cancer patients receiving chemotherapy: a neglected side effect?. Oncologist 2010;15:913-20.

20. IJpma I, Timmermans ER, Renken RJ, Ter Horst GJ, Reyners AK. Metallic taste in cancer patients treated with systemic therapy: A questionnaire-based study. Nutr Cancer 2017;69:140-5.

21. Strasser F, Demmer R, Böhme C, Schmitz SF, Thuerlimann B, Cerny T, et al. Prevention of docetaxel- or paclitaxel associated taste alterations in cancer patients with oral glutamine: a randomized, placebo-controlled, double-blind study. Oncologist 2008;13(3):337-46.

22.Sözeri E, Kutlutürkan S.Taste Alteration in $\mathrm{Pa}$ tients Receiving Chemotherapy. J Breast Health 2015;11:81-7.

23. Farrell C, Brearley SG, Pilling M, Molassiotis A. The impact of chemotherapy-related nausea on patients' nutritional status, psychological distress and quality of life. Support Care Cancer 2013;21:59-66.

24. Yamagishi A, Morita T, Miyashita M, Kimura F. Symptom prevalence and longitudinal follow-up in cancer outpatients receiving chemotherapy. J Pain Symptom Manage 2009;37:823-30.

25. Boussios S, Pentheroudakis G, Katsanos K, Pavlidis N. Systemic treatment-induced gastrointestinal toxicity: incidence, clinical presentation and management. Ann Gastroenterol 2012;25:106-18.

26. Hovan AJ, Williams PM, Stevenson-Moore P, Wahlin YB, OhrnK E, Elting LS, et a.l A systematic review of dysgeusia induced by cancer therapies. Support Care Cancer 2010;18:1081-7.

27. Turcott JG, Juárez-Hernández E, De la Torre-Vallejo M, Sánchez-Lara K, Luvian-Morales J, Arrieta O. Value: Changes in the Detection and Recognition Thresholds of Three Basic Tastes in Lung Cancer Patients Receiving Cisplatin and Paclitaxel and Its Association with Nutritional and Quality of Life Parameters. Nutr Cancer 2016;68(2):241-9.

28. Bernhardson BM, Tishelman C, Rutqvist LE. Taste and smell changes in patients receiving cancer chemotherapy: distress, impact on daily life, and self-care strategies. Cancer Nurs 2009;32:45-54. 